\title{
Effect of various types of dietary fibre on gastric emptying in growing pigs
}

\author{
By ANNA L. RAINBIRD* AND A. G. LOW \\ National Institute for Research in Dairying $\dagger$, Shinfield, Reading, Berks RG2 $9 A T$
}

(Received 4 January 1985 - Accepted 18 July 1985)

1. Five pigs initially of $40-50 \mathrm{~kg}$ live weight were fitted with simple gastric cannulas which permitted complete evacuation and sampling of gastric digesta once daily.

2. The effects of addition of four types of dietary fibre (wheat bran (WB; $40 \mathrm{~g} / \mathrm{kg}$ ), sodium carboxymethylcellulose (CMC; $40 \mathrm{~g} / \mathrm{kg}$ ), high-methoxy citrus pectin ( $\mathrm{Pe} ; 40 \mathrm{~g} / \mathrm{kg})$ and granulated guar gum $(\mathrm{G} ; 40 \mathrm{~g} / \mathrm{kg})$ ) on gastric emptying of a semi-purified diet during $4 \mathrm{~h}$ following a meal were measured.

3. Each of the test diets and the control diet (C) were given to each pig for 1 week using a $5 \times 5$ Latin-square arrangement. Digesta were collected before and $0 \cdot 5,1,2$ or $4 \mathrm{~h}$ after feeding on the last $5 \mathrm{~d}$ of each week.

4. The mean gastric $\mathrm{pH}$ was not significantly affected by diet except $2 \mathrm{~h}$ after feeding (CMC higher than $\mathrm{C}$ ) and $4 \mathrm{~h}$ ( $\mathrm{Pe}, \mathrm{G}$ and $\mathrm{CMC}$ higher than $\mathrm{C})$.

5. Compared with diet $\mathrm{C}$, the rate of gastric emptying of digesta was significantly slower for diet $\mathrm{G}, 1,2$ and $4 \mathrm{~h}$ after feeding, and 2 and $4 \mathrm{~h}$ after feeding for diet $\mathrm{CMC}$.

6. The rates of gastric emptying of digesta components were not significantly reduced by dietary fibre except for dry matter (DM) (diet CMC $2 \mathrm{~h}$ and diet B $4 \mathrm{~h}$ after feeding), total nitrogen (TN)(diet $\mathrm{G} 2 \mathrm{~h}$ after feeding) and total glucose (diet Pe $2 \mathrm{~h}$ after feeding).

7. There were no significant effects of diet on trichloroacetic-acid-soluble $N: T N$.

8. When gastric emptying was expressed in terms of half-time $\left(T_{50}\right)$ values, significant increases (compared with diet C) were found for digesta (diets G and CMC), DM (diet WB) and TN (diet G).

9. The apparent viscosity of the gastric digesta was significantly higher when diets $\mathrm{Pe}, \mathrm{G}$, and $\mathrm{CMC}$ were given than diets $\mathrm{C}$ or WB. Diets Pe and CMC were very viscous in the meal before ingestion, but diet $\mathrm{G}$ was not; its high viscosity developed after it had reached the stomach.

10. It is concluded that although those types of dietary fibre which increased meal or gastric viscosity reduced the rate of gastric emptying of digesta, this effect was confined to the liquid phase, because DM, total glucose and TN emptying were largely unaffected. The hypothesis that a reduced rate of gastric emptying may be an important determinant of the decreased rates of glucose absorption observed when such sources of dietary fibre are eaten is not supported by the results presented.

In recent years there has been great interest in the use of high-carbohydrate-high-fibre diets for the treatment of diabetics (Jenkins et al. 1980; Simpson, 1981). Of particular interest are those soluble forms of dietary fibre which increase meal viscosity (Jenkins \& Wolever, 1981) and reduce the peak concentration of peripheral blood glucose levels after a test meal (Jenkins et al. 1978); it was suggested that this effect might be due, at least in part, to a reduction in the rate of gastric emptying. However, not all forms of dietary fibre are of equal value in reducing postprandial hyperglycaemia and hyperinsulinaemia when added to a test meal in man (Jenkins et al. 1978).

Jenkins et al. (1978) found that powdered guar gum was the most effective form of dietary fibre for reducing postprandial hyperglycaemia when tested on a weight-for-weight basis in human subjects. Addition of similar powdered guar gums to low-volume liquid test meals in man (Blackburn et al. 1984), the rat (Leeds et al. 1979) and the pig (Rainbird, 1986) reduced the rate of gastric emptying. However, when guar gum was added to a high-starch meal given to pigs, delays were found in the rate of emptying of digesta but not of dry matter

\footnotetext{
* Present address: Waltham Centre for Pet Nutrition, Freeby Lane, Waltham-on-the-Wolds, Melton Mowbray, Leics LE14 4RS.

† Now the Animal and Grassland Research Institute, Shinfield, Reading, Berks RG2 9AQ.
} 
(DM) (Rainbird, 1986; Rainbird \& Low, 1986). The property of guar gum to increase meal viscosity is thought to be of great importance in its mode of action. However, there is a lack of information on the possible effects of other types of dietary fibre on gastric emptying. The objective of the present study was to examine the relation between meal viscosity and gastric emptying in pigs using two sources of polysaccharides which do increase meal viscosity (pectin and sodium carboxymethylcellulose) and two which do not ('LejGuar', a granulated formulation of guar gum, and wheat bran).

\section{EXPERIMENTAL METHODS}

\section{Animals and surgery}

Five male Large White $\times$ Landrace pigs, initially of $40-50 \mathrm{~kg}$ live weight and surgically prepared with a simple gastric cannula as described by Low et al. (1985) were used. The animals were housed in metabolism crates throughout the experiment. Gastric-emptying studies began at least $14 \mathrm{~d}$ after surgery.

\section{Animal weighing and feeding}

This has been described in detail by Rainbird \& Low (1986). The air-dry diet was mixed with water $(1: 2 \cdot 5, \mathrm{w} / \mathrm{v}) 15 \mathrm{~min}$ before feeding and offered twice daily at 09.00 and 17.00 hours.

\section{Composition of diet}

The basal diet was of a high-fat semi-purified type as used in previous studies in pigs (Rainbird \& Low, 1986). Four types of dietary fibre were added to this diet: wheat bran (WB, $40 \mathrm{~g} / \mathrm{kg}$ diet; Wholefoods, T. Neville \& Partners, Witney, Oxon); a granulated form of guar gum (G, $40 \mathrm{~g} / \mathrm{kg}$ diet; 'LejGuar'; Britannia Pharmaceuticals, Reigate, Surrey); pectin (Pe, $60 \mathrm{~g} / \mathrm{kg}$ diet; citrus pectin USP; H. P. Bulmer Ltd, Hereford) and high-viscosity sodium carboxymethylcellulose (CMC, $40 \mathrm{~g} / \mathrm{kg}$ diet; BDH Chemicals Ltd, Poole, Dorset). The amounts of $\mathrm{Pe}$ and $\mathrm{CMC}$ used provided diets of similar viscosity to the diet containing $40 \mathrm{~g}$ guar gum $/ \mathrm{kg}$ diet used in previous studies (Rainbird \& Low, 1986). 'LejGuar', unlike other types of guar gum, does not appreciably increase meal viscosity but it is known to reduce postprandial hyperglycaemia in man (Smith \& Holm, 1982). Each pig received one diet per week in a Latin square design.

\section{Collection of gastric digesta}

The sampling procedure has been described in detail by Low et al. (1985) and Rainbird \& Low (1986). One sample was taken per pig per day (Monday-Friday) in a randomized order just before or at $0 \cdot 5,1,2$ or $4 \mathrm{~h}$ after the start of the morning meal.

The digesta evacuated from the stomach by suction were termed the evacuated digesta. The water used to remove any residual digesta in the stomach after removal of the evacuated digesta was termed the rinse water. After weighing and sampling the digesta, the remainder was returned to the pig through the gastric cannula.

\section{Analytical methods}

The methods for measuring $\mathrm{pH}$, dry matter (DM), total nitrogen (TN), trichloroacetic-acid (TCA)-soluble $\mathrm{N}$, total glucose, and viscosity of the digesta were described by Rainbird \& Low (1986). 
Table 1. Percentage of total dry matter recovered in evacuated gastric digesta before and $0 \cdot 5,1,2$ or $4 \mathrm{~h}$ after pigs received diets containing different types of dietary fibre

(Mean values for five pigs/treatment)

\begin{tabular}{llllll}
\hline \multicolumn{1}{c}{ Diet } & \multicolumn{5}{c}{ Period after feeding (h) } \\
\cline { 2 - 6 } & 0 & $0 \cdot 5$ & 1 & 2 & 4 \\
\hline Control & 61 & 93 & 84 & 83 & 78 \\
Control + pectin & 63 & 25 & 35 & 42 & 69 \\
Control +'LejGuar' & 52 & 82 & 80 & 77 & 79 \\
Control +wheat bran & 72 & 93 & 86 & 81 & 81 \\
Control + CMC & 59 & 55 & 62 & 69 & 80 \\
\hline
\end{tabular}

CMC, carboxymethylcellulose.

\section{Expression of results}

$\mathrm{pH}$ values are direct measurements. The weights of digesta, DM, TN and total glucose in the stomach at different times after feeding are expressed as percentages of the respective intake values, less the amounts found in the stomach in the prefeeding sample. The half emptying times $\left(T_{50}\right)$ of digesta, DM, TN and total glucose were also calculated. TCA-soluble $\mathrm{N}$ is expressed relative to the TN content of the same sample.

\section{Statistical analysis}

The effect of dietary fibre on the experimental indices was assessed by analysis of variance of a $5 \times 5$ Latin-square.

RESULTS

The animals grew normally and remained in good health throughout the experiment. There were no problems of leakage from the cannulas.

\section{Recovery of $D M$ in evacuated digesta}

The weight of DM in the initial evacuated digesta, before the stomach was washed out with water, expressed as a percentage of the total DM recovered (including rinses) at that time is shown in Table 1. Larger amounts were recovered from diets which gave meals of low viscosity (diets $\mathrm{C}$, WB and $\mathrm{G}$ ) than for the diets $\mathrm{CMC}$ and $\mathrm{Pe}$, which gave more viscous meals: the percentage of the total DM which was recovered in the evacuated digesta increased with time after feeding for these diets, while the viscosity decreased. The percentage of the total gastric DM recovered in the evacuated digesta was lower before feeding than after feeding, and is consistent with the results of Rainbird \& Low (1986).

$$
p H
$$

The $\mathrm{pH}$ of the evacuated gastric digesta is shown in Table 2. Before feeding, the gastric $\mathrm{pH}$ was very low. It rose after feeding to maximum values $0.5 \mathrm{~h}$ later and then fell with increasing time after feeding. The $\mathrm{pH} v$. time curves for diets $\mathrm{C}$ and $\mathrm{WB}$ were very similar and not significantly different up to $4 \mathrm{~h}$ after feeding. The $\mathrm{pH} v$. time curves for diets $\mathrm{Pe}$ and $G$ were similar to that of the control for the first $2 \mathrm{~h}$ after feeding. However, $4 \mathrm{~h}$ after feeding, the mean gastric $\mathrm{pH}$ was significantly higher for diets $\mathrm{CMC}, \mathrm{Pe}$ and $\mathrm{G}$ than for $\operatorname{diet} \mathrm{C}$. 


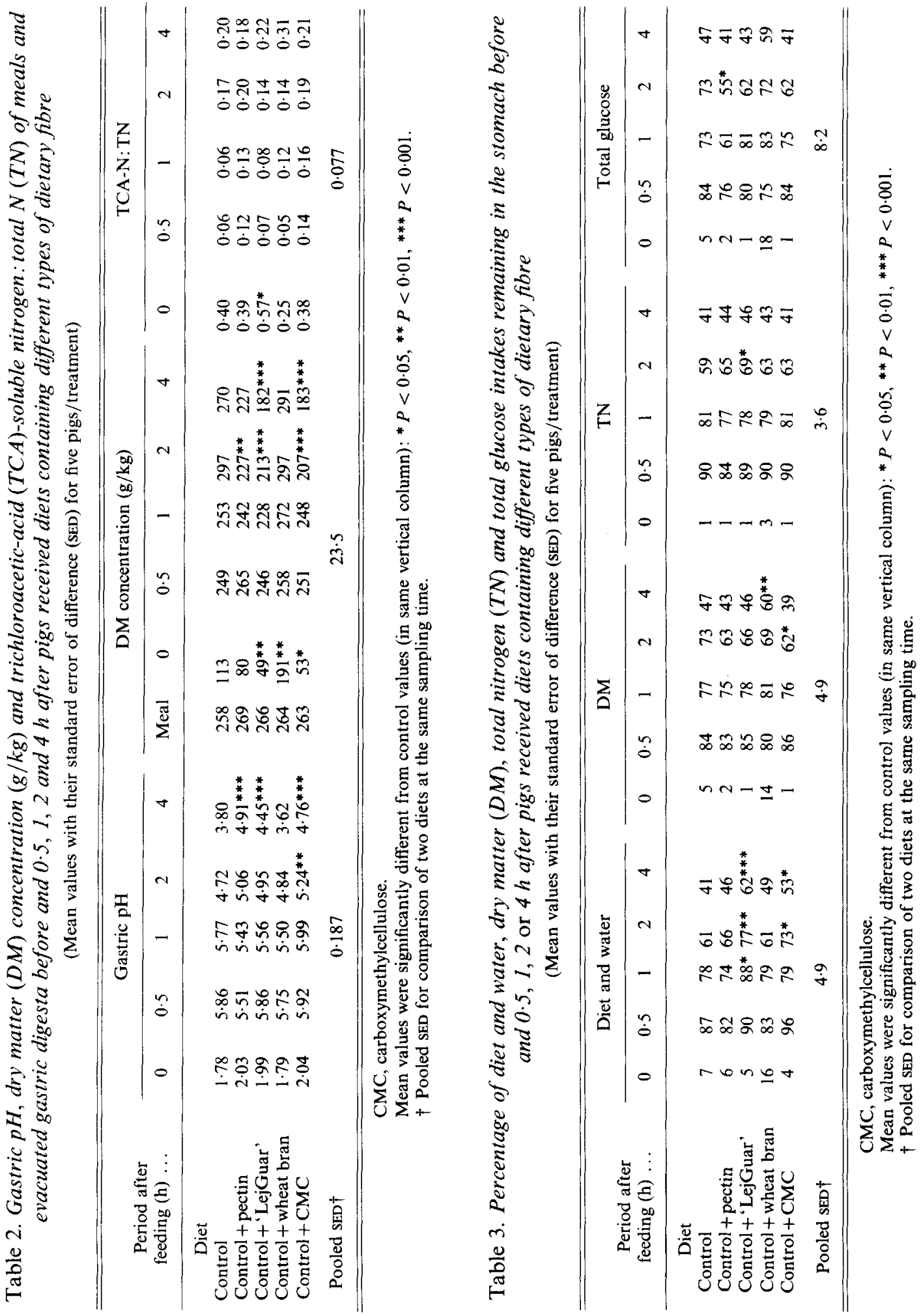




\section{Weight of digesta}

The percentage of the diet and water intake which remained in the stomach is shown in Table 3. There was very little digesta in the stomach before the morning meal except in the case of diet WB (when $16.1 \%$ remained).

It can be seen that 'LejGuar' (diet G) had the greatest effect in reducing the rate of emptying of digesta from the stomach. CMC was only effective in this respect 2 and $4 \mathrm{~h}$ after feeding, while addition of pectin and wheat bran to the diet (diets Pe and WB) had very little effect on the gastric emptying of digesta.

\section{$D M$}

The percentage of the DM intake remaining in the stomach is shown in Table 3. Very little DM was found in the stomach before the morning meal except from diet WB. This corresponds with the larger volume of digesta found in the stomach before feeding with this diet. The pattern of DM emptying was similar for all diets, and was not consistently affected by any of the sources of dietary fibre during the $4 \mathrm{~h}$ period of sampling.

\section{DM concentration $(\mathrm{g} / \mathrm{kg})$ of evacuated gastric digesta}

Table 2 shows the DM concentration of the meals and of the evacuated gastric digesta. In the case of diets $\mathrm{C}$ and WB, the DM concentration of the evacuated digesta increased with time after feeding. However, diets Pe, G and CMC showed a different pattern: the percentage DM of the evacuated gastric digesta continued to fall with time after feeding.

\section{$T N$}

The percentage of the TN intake remaining in the stomach is shown in Table 3. As with $D M$, very little $T N$ was found in the stomach before the morning feed. The pattern of emptying after the meal was similar for all five diets. The only significant difference between diets occurred $2 \mathrm{~h}$ after feeding when more TN remained in the stomach after diet $\mathrm{G}$ than after diet $\mathrm{C}$.

\section{TCA-soluble $N: T N$}

Values for TCA-soluble $\mathrm{N}$ :TN (in the evacuated gastric digesta) are shown in Table 2. The only significant difference between the five diets was seen in the prefeed gastric digesta. The digesta derived from diet $\mathrm{G}$ had a significantly higher ratio than digesta from diet $\mathrm{C}$. The ratio had fallen to $0.05-0.14,0.5 \mathrm{~h}$ after feeding but gradually increased in all diets to $0 \cdot 18-0 \cdot 31,4 \mathrm{~h}$ after feeding.

\section{Total glucose}

The percentage of the total glucose intake which remained in the stomach is shown in Table 3. There was very little total glucose in the stomach before the morning feed, except from diet WB: in this case $18 \%$ of the previous meal intake of total glucose remained in the stomach. This high value corresponded with the relatively large amount of DM found in the stomach before feeding on this diet.

The addition of dietary fibre to the diet had little effect on the emptying of total glucose from the stomach. The only significant difference observed followed the addition of pectin to the diet (diet $\mathrm{Pe}$ ), when a smaller percentage of total glucose intake was found in the stomach than in the case of diet $\mathrm{C}, 2 \mathrm{~h}$ after feeding. The emptying of total glucose, largely present in the form of starch, from the stomach appeared to follow a similar pattern to the emptying of DM from the stomach. 
Table 4. Half emptying times $\left(\mathrm{T}_{50}\right.$, min) for the emptying of digesta, dry matter $(D M)$, total nitrogen $(T N)$ and total glucose from the stomach after pigs received diets containing different types of dietary fibre

(Mean values with their standard errors of difference (SED) for five pigs/treatment)

\begin{tabular}{lcccc}
\hline \multicolumn{1}{c}{ Diet } & Digesta & DM & TN & $\begin{array}{c}\text { Total } \\
\text { glucose }\end{array}$ \\
\hline Control & 180 & 239 & 180 & 249 \\
Control + pectin & 216 & 192 & 199 & 171 \\
Control +'LejGuar' & $350^{* * *}$ & 210 & $219^{* *}$ & 193 \\
Control + wheat bran & 207 & $349^{*}$ & 190 & 258 \\
Control +CMC & $280^{* *}$ & 177 & 185 & 181 \\
Pooled SED & 34.0 & $43 \cdot 5$ & $12 \cdot 2$ & $38 \cdot 7$ \\
\hline \hline
\end{tabular}

$\mathrm{CMC}$, carboxymethylcellulose.

Mean values were significantly different from control values (in same vertical column): ${ }^{*} P<0.05, * * P<0 \cdot 01$, *** $P<0.001$.

$\mathrm{T}_{50}$

The mean time taken for half the intake of food (diet and water) or of a particular nutrient to empty from the stomach is shown in Table 4. The emptying of digesta following diet $\mathrm{C}$ had a mean $T_{50}$ of $180 \mathrm{~min}$. The addition of dietary fibre to the diet increased the mean $T_{50}$ values but this was only statistically significant for diets $\mathrm{G}$ and CMC which had mean $T_{50}$ values of 350 and $280 \mathrm{~min}$ respectively. These results suggest that addition of 'LejGuar' and $\mathrm{CMC}$ to the diet (diets $\mathrm{G}$ and $\mathrm{CMC}$ ) reduced the rate of emptying of digesta from the stomach.

Addition of pectin, 'LejGuar' and CMC to the diet (diets Pe, G and CMC) did not significantly reduce the $T_{50}$ for the emptying of $\mathrm{DM}$, but addition of bran to the diet (diet WB) significantly increased the mean $T_{50}$ suggesting that bran reduced the rate of emptying of DM from the stomach.

Addition of dietary fibre to the diet had little effect on the mean $T_{50}$ for the emptying of TN from the stomach. The only significant difference was an increase as a result of 'LejGuar' addition to the diet (diet $\mathrm{G}$ ). The $T_{50}$ values indicate that the emptying of TN from the stomach followed the pattern of digesta movement for diets $\mathrm{C}$ and WB but for diets $\mathrm{Pe}, \mathrm{G}$ and $\mathrm{CMC}$ it appeared to follow the movement of DM.

None of the types of dietary fibre added to the diet significantly affected $T_{50}$ for the emptying of total glucose, which was similar to DM. It is notable that there was very great variability in the $T_{50}$ values for the emptying of digesta, DM and total glucose; lower values were found for TN. Thus, although there were large differences in the mean $T_{50}$ for the emptying of DM, for example $239 \mathrm{~min}$ for diet C compared with $177 \mathrm{~min}$ for diet $\mathrm{CMC}$, these were not statistically significant.

\section{Viscosity}

Addition of $\mathrm{Pe}$ and $\mathrm{CMC}$ to the meal markedly increased its apparent viscosity (diet $\mathrm{C}$ $0.053 \mathrm{~N} \mathrm{~s} / \mathrm{m}^{2}$, diet Pe $4.749 \mathrm{~N} \mathrm{~s} / \mathrm{m}^{2}$, diet CMC $5.845 \mathrm{~N} \mathrm{~s} / \mathrm{m}^{2}$ ) whilst bran and 'LejGuar' had little effect (diet WB $0.036 \mathrm{~N} \mathrm{~s} / \mathrm{m}^{2}$, diet $\mathrm{G} 0.641 \mathrm{~N} \mathrm{~s} / \mathrm{m}^{2}$ ). The effect of the different types of dietary fibre on the apparent viscosity of the evacuated gastric digesta is shown in Fig. 1. 


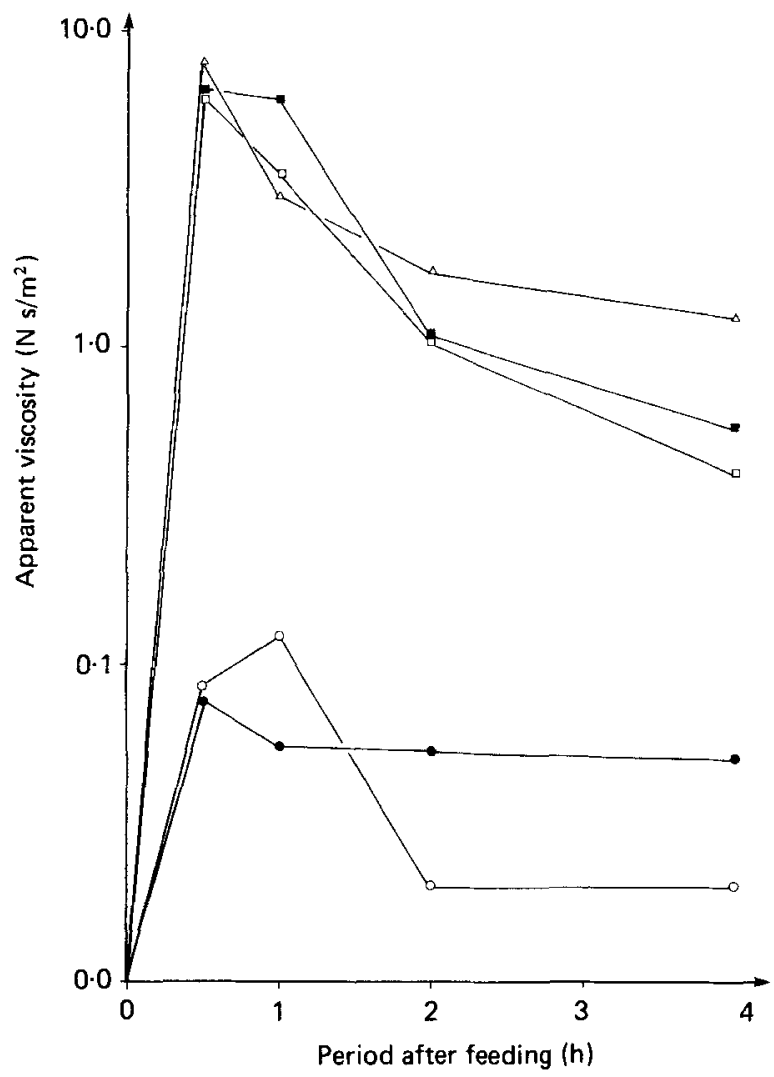

Fig. 1. Semi-log plot of apparent viscosity of evacuated gastric digesta before and $0.5,1,2$ and $4 \mathrm{~h}$ after pigs received diets containing different types of dietary fibre $(n)$ ). (O), Control; $(\odot)$ wheat bran; $(\square)$, 'LejGuar' granulated guar gum; ( $)$, carboxymethylcellulose (CMC); $\triangle$ ), pectin. Standard error of difference $0 \cdot 19$ for comparison of two diets at the same sampling time. The viscosity of the evacuated gastric digesta was significantly higher $(P<0.001) 0.5,1,2$ and $4 \mathrm{~h}$ after addition of pectin, CMC and "LejGuar" to the diet compared with the control diet.

Because of the wide variation in the viscosity of the digesta obtained at different times after feeding, the results have been plotted on a semi-log scale.

The differences in the viscosity of the meals did not affect the viscosity of the gastric digesta found in the stomach before feeding, which was always low. The viscosity of the gastric digesta from diets $\mathrm{C}$ and $\mathrm{WB}$ was similar and low at all times. At $0.5 \mathrm{~h}$ after consumption of diets $\mathrm{Pe}$ and $\mathrm{CMC}$ the mean apparent viscosity of gastric digesta was only marginally higher than that of the ingested meal. The evacuated gastric digesta had a significantly higher mean apparent viscosity $0 \cdot 5,1,2$ and $4 \mathrm{~h}$ after consumption of diets $\mathrm{Pe}$ and $\mathrm{CMC}$ than of diet $\mathrm{C}$, although viscosity decreased with time after feeding.

Diet $\mathrm{G}$ had a very low mean apparent viscosity when consumed, but the viscosity increased in the stomach to give gastric digesta with a mean apparent viscosity only slightly lower than that after consumption of diet CMC but significantly higher than the control. The viscosity of the digesta then decreased with time after feeding, but was always significantly higher than the control. 


\section{DISCUSSION}

\section{Technique}

It was possible to remove the majority of the stomach contents by suction alone (before rinsing) following consumption of diets $\mathrm{C}, \mathrm{G}$ and $\mathrm{WB}$ (Table 1). The lowest recoveries, found with diet $\mathrm{Pe}$, were related to the viscous nature of the diet. Thus as viscosity decreased with time after feeding, so recovery of stomach contents by suction increased; these results are consistent with those of Rainbird \& Low (1986) when guar gum was added to the diet.

\section{$p H$}

The low gastric $\mathrm{pH}$ observed before feeding all diets and the $\mathrm{pH}$ values after consumption of diet $C$ were similar to those found in a previous study (Rainbird \& Low, 1986).

The higher $\mathrm{pH}$ values seen $4 \mathrm{~h}$ after feeding diets containing dietary fibre than after diet $\mathrm{C}$ may have been due to reduced gastric acid secretion but this was not measured directly in the present study. However, in the only other report of the effect of dietary fibre on gastric secretion and $\mathrm{pH}$ in man, Tadesse (1982) found that pectin and CMC did not alter the volume or type of secretion although they increased gastric $\mathrm{pH} 30 \mathrm{~min}$ after consumption of the meal (the only time studied); this change in gastric $\mathrm{pH}$ was found to be due to an increase in the relative amount of unionized (combined) hydrogen in the gastric digesta. This may also, at least in part, be the explanation for the higher gastric $\mathrm{pH}$ values observed in the present study when dietary fibre was added to the diet.

\section{Digesta}

The pattern of emptying of diet $\mathrm{C}$ in the present study followed a more clearly exponential pattern than that observed by Rainbird \& Low (1986) and was similar to that observed in pigs by Cuber et al. (1980). The reasons for this appear to be less variation between animals and an absence of missing values.

From Table 3 it can be seen that different types of dietary fibre had different effects on the emptying of digesta. 'LejGuar' (diet G) reduced the rate of emptying of digesta more than the other types of dietary fibre: a possible explanation for this became clear when the viscosity of digesta was measured. Although diet $G$ was of low viscosity, it was found that gastric digesta were of a much higher viscosity, and similar to that of digesta after consumption of diet CMC.

Pectin (diet $\mathrm{Pe}$ ), although giving rise to a very viscous gastric digesta, had no effect on the gastric emptying of digesta. This was not expected as the other types of dietary fibre which increased the viscosity of digesta in pigs (i.e. CMC, 'LejGuar' and guar gum) reduced the rate of emptying of digesta. However, it is notable that in man, addition of pectin to a glucose drink increased the emptying rate of digesta compared with the control (Tadesse, 1982).

The effects of adding pectin to a meal in man and the pig challenge the view that the viscosity and water-holding capacity of the dietary fibre are important determinants of the rate of gastric emptying of digesta. Ehrlein \& Prove (1982) showed that increasing the viscosity of a test meal with potato starch granules reduced the rate of emptying of digesta, suggesting that viscosity rather than the presence of dietary fibre was the important factor. It is, however, possible that the reduction in the rate of emptying of digesta in pigs by guar gum, CMC and 'LejGuar' was due in part to their water-holding capacity. However, Stephen \& Cummings (1979) found pectin to have a greater in vitro water-holding capacity than guar gum or CMC. Thus either the water-holding capacity of a dietary fibre is not a very important factor in reducing the rate of emptying of digesta, or the pectin used in the present study had a low water-holding capacity. At this point it may also be noted that 
the measurement of the water-holding capacity of different types of dietary fibre remains a somewhat uncertain procedure.

The fact that bran did not affect the gastric emptying of digesta may well have been related to its lack of effect in reducing postprandial glycaemia in man (Jenkins et al. 1978).

Although a change in gastric secretion cannot be ruled out, differences in the rate of emptying of digesta from the stomach after addition of different types of dietary fibre to the diet seem to be due to different rates of emptying of liquid and solids, particularly in relation to the control diet (diet $\mathrm{C}$ ). It was noted in the laboratory that the DM or solids in diet $C$ rapidly settled out on the bottom of a beaker, whereas the DM of viscous diets was held in uniform suspension. Since the emptying of DM was similar with all diets, the differences found were therefore due to changes in liquid emptying. Although the water-holding capacity of the dietary fibre may be important in this respect, it does not appear to have been the only factor involved because neither pectin nor bran additions (diets Pe and WB) caused significant changes in the pattern of digesta emptying.

\section{$D M$}

The only type of dietary fibre which markedly decreased the rate of emptying of DM from the stomach was bran (diet WB), as judged by the $T_{50}$ value. However, when the pattern of emptying of DM is examined (Table 3 ) it can be seen that the high $T_{50}$ value for diet WB was due almost entirely to a reduction in emptying seen $4 \mathrm{~h}$ after feeding. This is an example of the way in which $T_{50}$ values can give misleading information on changes in the pattern of gastric emptying. From visual examination of the samples collected $4 \mathrm{~h}$ after feeding diet WB, it seemed that bran formed a larger proportion of the DM in the samples collected earlier. Thus the delay in emptying of DM may have been due to a slower emptying of the bran itself from the stomach.

\section{DM of evacuated digesta}

The lower DM concentration of the initially evacuated digesta after addition of 'LejGuar', CMC and pectin to the diet (diets G, CMC and Pe) (Table 2) was similar to that observed with powdered guar gum (Rainbird \& Low, 1986). It appears that those types of dietary fibre which increase the viscosity of digesta tended to have the greatest effect in reducing gastric digesta DM concentrations. For further discussion of this topic, see Rainbird \& Low (1986).

\section{$T N$}

The gastric emptying pattern of TN from diets $\mathrm{C}$ and $\mathrm{WB}$ appeared to be similar to that of digesta whereas, in the case of diets $\mathrm{Pe}, \mathrm{CMC}$ and $\mathrm{G}, \mathrm{TN}$ appeared to flow with the DM. This difference may be related to the viscosity of the diets. In the case of the viscous diets the digesta appeared to be homogeneous but in the case of diets WB and C some settling of DM may have occurred in the stomach while the soluble TN still emptied from the stomach. Despite these differences the only type of dietary fibre which significantly reduced the emptying of TN was 'LejGuar' (diet G). Although the difference was small, the result was significant and was associated with a low standard error of difference.

\section{TCA-soluble $N: T N$}

The proportion of TCA-soluble $\mathrm{N}$ in the TN increased with time after feeding (Table 2) for all diets. This is consistent with the findings of Rainbird \& Low (1986). This was due to the progressive intragastric hydrolysis of dietary proteins. The similarity of the TCA-soluble $\mathrm{N}$ : TN values between treatments (at a given time) suggests that the digestion of protein by pepsin in the stomach was not modified by dietary fibre. It was thought that the viscous nature of digesta after diets $\mathrm{CMC}$, Pe and $\mathrm{G}$ might have decreased enzyme- 
substrate contact, thus slowing digestion and decreasing TCA-soluble $\mathrm{N}$ levels. Although this does not appear to have occurred, it may be that there was greater secretion of pepsin to achieve the same rate of digestion.

\section{Total glucose}

The emptying of total glucose in the present study (Table 3) was slower than that observed by Rainbird \& Low (1986) but this seems likely to have been due to slower emptying of DM which was also observed. The emptying of total glucose from all diets followed the same pattern as that of the DM; this is consistent with the results of the previous experiment and those of Cuber et al. (1980). None of the sources of dietary fibre used had any effect on the emptying of total glucose, suggesting that a reduction in the rate of gastric emptying of glucose is not responsible for the flattening of the postprandial blood glucose curve, which these sources of dietary fibre (other than bran) induce.

\section{Viscosity}

The drawbacks of the technique used to measure viscosity have already been discussed (Rainbird \& Low, 1986). Both diets C and WB gave rise to digesta of a very-low viscosity which was similar in both cases to that of the meal ingested. Although the addition of 'LejGuar' to the diet (diet G) did not increase meal viscosity, it did lead to gastric digesta of similar viscosity to that produced by ingestion of diet CMC. This pattern of viscosity development in the stomach contrasts with the immediate increase in viscosity of a liquid meal before consumption when conventional powdered guar gum is used (Rainbird \& Low, 1986) and is due to a new processing technique. This granulated form of guar gum was devised to make the consumption of guar gum more acceptable for humans by reducing the viscosity of the meal. It appears that viscosity of meals containing 'LejGuar' is low at the neutral $\mathrm{pH}$ of the meal but after contact with gastric acid hydration begins and the viscosity increases. The higher viscosity of gastric digesta following consumption of diets $\mathrm{CMC}$ and Pe than of the corresponding meal may also be attributed to the initial acidic $\mathrm{pH}$ of the stomach. It can be concluded that addition of different types of dietary fibre to a diet may have a marked effect on both the viscosity of the meal eaten and the gastric digesta after feeding, but meals of similar viscosity do not necessarily produce gastric digesta of similar viscosities.

The results indicate that the addition of dietary fibre to the diet, particularly those forms which increased the viscosity of gastric digesta, modified the postprandial gastric $\mathrm{pH}$ profile, but not the emptying of DM (including TN and total glucose, which follow similar patterns to DM). The rate of emptying of digesta from the stomach was reduced by the addition of CMC and 'LejGuar'; this was due mainly to a reduced emptying of water, reflected in the lower percentage DM content of digesta derived from diets containing these sources of dietary fibre. We conclude that the reduced postprandial blood glucose concentrations seem in other studies after addition of dietary fibre to the diet may be due to factors other than an altered pattern of gastric emptying.

The authors would like to thank Dr I. E. Sambrook, Mrs R. J. Elliott, Mr H. A. Smith and Mr A. R. Jones and his staff for their assistance with various aspects of this study. ALR gratefully acknowledges receipt of an Agricultural Research Council Postgraduate Research Studentship. The citrus pectin was kindly donated by Dr J. Buckle of H. P. Bulmer Ltd. 


\section{REFERENCES}

Blackburn, N. A., Redfern, J. S., Jarjis, H., Holgate, A. M., Hanning, I., Scarpello, J. H. B., Johnson, I. T. \& Read, N. W. (1984). Clinical Science 66, 329-336.

Cuber, J.-C., Laplace, J.-P. \& Villiers, P. A. (1980). Reproduction, Nutrition, Developpement 20, $1161-1172$.

Ehrlein, H.-J. \& Prove, J. (1982). Quarterly Journal of Experimental Physiology 67, 419-425.

Jenkins, D. J. A. \& Wolever, T. M. S. (1981). Proceedings of the Nutrition Society 40, 227-235.

Jenkins, D. J. A., Wolever, T. M. S., Bacon, S., Nineham, R., Lees, A. R., Rowden, R., Love, M. \& Hockaday, T. D. R. (1980). American Journal of Clinical Nutrition 33, 1729-1733.

Jenkins, D. J. A., Wolever, T. M. S., Leeds, A. R., Gassull, M. A., Haisman, P., Dilawari, J., Goff, D. V., Metz, G. L. \& Alberti, K. G. M. M. (1978). British Medical Journal i, 1392-1394.

Leeds, A. R., Bolster, N. R., Andrews, R. \& Truswell, A. S. (1979). Proceedings of the Nutrition Society 38, 44 A.

Low, A. G., Pittman, R. J. \& Elliott, R. J. (1985). British Journal of Nutrition 54, 437-447.

Rainbird, A. L. (1986). British Journal of Nutrition 55, 87-98.

Rainbird, A. L. \& Low, A. G. (1986). British Journal of Nutrition 55, 99-109.

Simpson, H. C. R. (1981). Proceedings of the Nutrition Society 40, 219-225.

Smith, U. \& Holm, G. (1982). Atherosclerosis 45, 1-10.

Stephen, A. M. \& Cummings, J. H. (1979). Gut 20, 722-729.

Tadesse, K. (1982). Journal of Physiology 332, 102 P. 